\title{
EVALUATING SWORDS: INTRODUCTION AND TRANSLATION OF A HOW-TO GUIDE FROM THE HAN-XIN PERIOD
}

\author{
Charles Sanft*
}

\begin{abstract}
This article introduces and translates an excavated text from the Juyan region here referred to as "Evaluating Swords." Dating to the Han-Xin period, it instructs its reader on how make a general determination of the quality of steel swords based on a visual inspection. The introduction to the translation discusses the background of the text, its present condition, and the problems of orthography and usage that complicate its understanding. A transcription and additional textual and interpretive commentary accompany the English translation of the text.
\end{abstract}

Sword, hold thy temper; heart, be wrathful still.

Shakespeare, Henry VI

\section{Introduction}

Need to buy a sword? If you do, chances are you will go online and find a maker that sword-buyers say good things about. If you are old-fashioned, you may consult a "book" (shu 書). More likely, though, you will peruse the ephemeral writings-blog posts, tweets, reviews-of swashbucklers in search of expert recommendations about makes and models. Maybe you will even visit a sword shop and seek the advice of its tattooed, locally-produced proprietor concerning the best sword brands and their specifications.

We live in a time of mass production. When we do research before a purchase, we base our decisions on the expectation of matching quality among a given maker's products and among different examples of a given product. Things in early China were more complicated. It is not

* Charles Sanft, 陳力強, University of Tennessee, email: charlessanft@gmail.com.

I presented a version of this article at a workshop at the University of Chicago Creel Center for Chinese Paleography on 7 November 2015. I thank Edward L. Shaughnessy, Robin D. S. Yates, and the other participants for their questions, comments, and suggestions. I am also grateful to Sarah Allan, Miranda Brown, William Boltz, and Matthias Richter for reading and commenting on draft versions of this article.

(C) The Society for the Study of Early China and Cambridge University Press 2016 
that makers never advertised their wares. Anthony Barbieri-Low has shown how masters and workshops marked their wares and sought to extend their reputations. ${ }^{1}$ Yet many utilitarian objects required evaluation on the basis of examining an available exemplar. For workaday items, there was nothing better for a buyer to rely upon, especially when life and death could depend on the choice. This article translates a short text that advises its reader in the selection of just this sort of item, a sword. It concentrates on just one thing: identifying a quality sword by examining the metal of its blade. The text as it comes to us is unlabeled. It begins by addressing its audience, "One who wishes to know whether a sword is good and old ..." 欲知劍利善故器者, which is too unwieldy to serve as a title. I will refer to it, on the basis of its content, as "Evaluating Swords."

Archaeologists recovered the wooden writing strips comprising "Evaluating Swords" from the area that they and historians refer to by the Han-era toponym Juyan 居延, which encompasses portions of present-day Gansu and Inner Mongolia. China's desert northwest has provided a variety of textual evidence of life at military-bureaucratic installations far from the centers of government and high culture. Scholars writing in Chinese and Japanese have used the materials from the Juyan area extensively in their research. Michael Loewe made seminal contributions to Chinese Studies in western languages through his work with them, and other scholars writing in European languages have since treated Juyan texts. It is nevertheless fair to say that much remains to be done in the study of material from the Han dynasty border regions.

Through its translation of "Evaluating Swords," I hope this article will add to our understanding of intellectual life in the hinterlands by providing an example of the sort of discursive text that circulated there in Han 漢 and Xin 新 times. This is, I suggest, an example of the kind of text that low-ranking soldiers and military bureaucrats would have encountered in their lives. "Evaluating Swords" also presents some interpretive difficulties that make it potentially interesting (or perhaps even useful) for scholars who work with paleographic sources, difficulties that I discuss in my introduction to the text.

1. Anthony Barbieri-Low, Artisans in Early Imperial China (Seattle: University of Washington Press, 2007).

2. On the possibilities for such men to read, see Robin D. S. Yates, "Soldiers, Scribes, and Women: Literacy among the Lower Orders in Early China," in Writing and Literacy in Early China: Studies from the Columbia Early China Seminar, ed. Li Feng and David Prager Branner (Seattle: University of Washington Press, 2011), 339-69. On the importance of "access," cf. David Johnson, "Chinese Popular Literature and Its Contexts," Chinese Literature: Essays, Articles, Reviews 3.2 (1981), 228. 


\section{Background of the Text}

Working as part of the famous Sino-Swedish expedition, Folke Bergman (1902-1946) visited the deserts of what is now western and northwestern China and Mongolia a number of times between 1927 and 1934. He recovered some 10,000 writing strips in the area of the Ejina 額濟納 River, which are known as the Juyan Han strips 居延漢簡. About half of those strips came from one site in modern Gansu, Pochengzi 破城子, called Mu-durbeljin in Mongolian. Bergman visited Pochengzi three times. Two of those visits were brief: one when Bergman was first traveling along the line of watchtowers marking Han-era defenses in the area, the other when he passed by during his final journey through the area in 1934. Bergman made the initial excavations at Pochengzi during his only extended stay there, his second visit. He arrived on 27 December 1930 and remained until the harsh conditions drove him away on 25 January 1931. What had initially seemed an unprepossessing mound turned out to be a Han dynasty border post and the most productive site that Bergman explored during his travels. His recovery of artifacts and manuscripts by the thousands from the Han structures there was the first part of this archaeological site's story. $^{3}$

Decades later, between 1972 and 1976, Chinese archaeologists made further excavations at Pochengzi. Their work was much more extensive than Bergman's. They excavated the central site, which is defined by a surrounding wall of packed earth that is roughly square at approximately 47.5 by 45.5 meters and 1.8 to 2 meters thick. This wall shows signs of having been repaired in ancient times. The site also contains a smaller fortified tower (zhang 障) on the northwest corner of the main enclosure, 23.3 meters per side, with adobe brick walls 4-4.5 meters thick. Within the walled enclosure are thirty-seven rooms, all having packed earth walls and floors of mixed mud and grass. The archaeologists recovered

3. Folke Bergman, "Travels and Archaeological Field-work in Mongolia and Sinkiang-A Diary of the Years 1927-1934," in History of the Expedition in Asia 19271935, Part IV General Reports of Travels and Field-work, by Folke Bergman, Gerhard Bexell, Birger Bohlin, and Gösta Montell (Göteborg: Elanders Boktryckeri Aktiebolag, 1945), 146-48; Bo Sommarström, Archaeological Researches in the Edsen-gol Region Inner Mongolia: Together with the Catalogue Prepared by Folke Bergman (Stockholm: Statens Etnografiska Museum, 1956), 44-83. Note that Sommarström worked on the basis of Bergman's materials after the latter's death. For that reason I accept Sommarström's information over Bergman's when there is a conflict.

Zhongguo shehui kexue yuan kaogu yanjiusuo 中國社會科學院考古研究所, ed., Juyan Han jian jiayiabian 居延漢簡甲乙編 (Beijing: Zhonghua, 1980), 291, has a list of Mongolian names and Chinese counterparts, which confirms the identity of Bergman's Mu-durbeljin as Pochengzi. 
3,434 wooden writing strips from the rooms and pits they dug within the area of the walled enclosure and tower, most from the northern part of the walled area. 4 These included "Evaluating Swords." Scholars generally call the manuscripts recovered during this second round of excavations the "new Juyan strips" (Juyan xin jian 居延新簡) - even today, when they are no longer particularly new. Still later finds in the same general region around the Ejina River from 1998 to 2002 are known as the Ejina Han strips 額濟納漢簡. ${ }^{5}$

Archaeologists found the strips containing "Evaluating Swords" in the northwestern part of the enclosure, in a pit that is referred to by the abbreviation E.P.T. 40. (E stands for Ejina, P for Pochengzi, and T for tanfang 探方, a numbered section of the excavation site, in this case 40.) ${ }^{6}$ Although "Evaluating Swords" has no date upon it, other materials from the same pit bear dates ranging from 9 B.C.E. to 21 C.E., giving a rough idea of when this copy of the text was buried. ${ }^{7}$ This provides a general dating of the manuscript to the late Western Han, Xin, or early Eastern Han period.

The authors of the first transcription of "Evaluating Swords" make a very important distinction between the date of the manuscript from Pochengzi and that of the text's creation. ${ }^{8}$ Based upon the copy's position and the layers of its location, presumably (although tacitly) with reference to the dated materials, they date the manuscript to late Wang Mang 王莽 (9-23 C.E.) or early Eastern Han (25-220 C.E.) times. They believe the content to date to the early Western Han. ${ }^{9}$

4. Gansusheng Juyan kaogudui 甘肅省居延考古隊, “Juyan Han dai yizhi de fajue he xin chutu de jiance wenwu" 居延漢代遺址的發掘和新出土的簡冊文物, Wenwu 1978.1, 2-3; and Gansusheng wenwu kaogu yanjiusuo 甘肅省文物考古研究所, et al., eds., Juyan xin jian 居延新簡 (Beijing: Zhonghua, 1994), 1-4.

5. See summary of the finds and later scholarship in Hao Jianping 郝建平, “Jin 30 nian lai Juyan Han jian yanjiu zongshu” 近 30 年來居延漢簡研究綜述, Ludong daxue xuebao (zhexue shehui kexue ban) 魯東大學學報 (哲學社會科學版) 29.3 (2012), 61-66.

6. These abbreviations are explained in Ma Yi 馬怡 and Zhang Rongqiang 張榮強, Juyan xinjian jiaoshi 居延新簡校釋 (Tianjin: Tianjin guji, 2013), i.

7. See the dates in the materials from that location in Ma Yi and Zhang Rongqiang, 125-47; see also, e.g., Ma Mingda 馬明達, Shuo jian conggao 說劍叢搞, rev. ed. (Beijing: Zhonghua, 2007), 40-42, who discusses the role of these materials as providing a terminus ante quem for "Evaluating Swords."

8. On this distinction in a somewhat different context, see Matthias L. Richter, The Embodied Text: Establishing Textual Identity in Early Chinese Manuscripts (Leiden: Brill, 2013), in particular 26-27.

9. Gansusheng bowuguan Han jian zhengli zu 甘肅省博物館漢簡整理組, “Juyan Han jian 'Xiang jian dao' ce shiwen” 居延漢簡 “相劍刀” 冊釋文, Dunhuangxue jikan 敦煌學輯刊 3 (1983), 79; see also Chen Li 陳力, “JJuyan xinjian' xiang lishan daojian 
The question of the content's specific time of creation is impossible to answer definitively, although a tentative general dating is possible. In his discussion of sword evaluation, Ma Mingda 馬明達 refers to the time from the Chunqiu 春秋 period to the Han as the "golden age" of swords in China. He attributes this to technological advances during the time, the spread of the study of sword theory and technique, and the function of swords as signs of social rank. Together with these things came connoisseurship, collecting, and high prices for rarities. That led in turn to the potential for counterfeiting valuable swords and the need for skilled assessment of examples. Lüshi chunqiu 呂氏春秋, from the late third century B.C.E., for instance, mentions this kind of identification as part of evaluating swords in considering the dangers of false semblances: "A sword evaluator worries about a sword's resembling Wugan” 相劍者之所患，患劍之似吳干者 without being that famous blade. ${ }^{10}$ These things are part of the intellectual background of "Evaluating Swords."11 It must be noted, however, that nowhere does "Evaluating Swords" show any interest in recognizing famous swords or avoiding false identifications. It is concerned only with judging the quality of particular examples.

Ma Mingda furthermore sees indications within "Evaluating Swords" that its content dates to early Western Han times. First, and as others have also noted, its descriptions apply to swords made from worked and treated steel, not bronze or plain iron. This means the text must date no earlier than the Western Han, when steel became important in China. ${ }^{12}$ According to Ma and others, there was moreover a shift in the style of sword around the middle of the Western Han. Whereas formerly a straight sword with a knob pommel called the jian 劍 had been most popular, around the middle of the Western Han the dao 刀 sabre, ${ }^{13}$ a sword with a blade that was usually slightly curved and had a ring at the pommel, supplanted it. Both terms appear in "Evaluating Swords," but the latter just once, while the former occurs repeatedly. This indicates the dao had not replaced the jian when this text was created. On

zhujian xuanshi” “居延新簡”相利善刀劍諸簡選釋,” Kaogu yu wenwu 考古與文物 2002.6, 70, and Zhong Shaoyi 鐘少異, “Gu xiang jian shu chu lun” 古相劍術媰論, Kaogu 考古 1994.4, 361, which cite this dating.

10. Chen Qiyou 陳奇猷, Lüshi chunqiu xin jiaoshi 呂氏春秋新校釋 (Shanghai: Shanghai guji, 2002), 22.1507 .

11. Ma Mingda, "Zhongguo gudai de xiang jian fa" 中國古代的相劍法, Wensh $i$ zhishi 文史知識 2000.1, 59-61.

12. See also Donald B. Wagner, Iron and Steel in Ancient China (Leiden: Brill, 1996), 195-97.

13. The translation of dao as sabre follows Wagner, Iron and Steel in Ancient China. 
the basis of these two things, Ma dates the content of "Evaluating Swords" to the first part of the Western Han. ${ }^{14}$

There is the final question of whether this manuscript text is a standalone composition or an extract from a larger work. Liu Jinhua 劉金華 proposes three possible origins: a late Western Han selection from earlier, sword-related texts; a record of contemporary experience with swords; or a selection from some other, no longer extant, contemporary sword text. ${ }^{15}$ Along similar lines, Ma Mingda suggests it might either record the experience of a sword evaluator or be an extract from a larger text on the appraisal of swords. ${ }^{16}$

Many readers have proposed that "Evaluating Swords" has a relationship with the title Xiang bao jian dao 相寶劍刀, which appears in the Han shu 漢書 “Yiwenzhi” 藝文志. ${ }^{17} \mathrm{Li}$ Ling 李零, for instance, uses the title from "Yiwenzhi" to denote the Juyan text. ${ }^{18}$ Zhong Shaoyi 鐘少異 brings the title from "Yiwenzhi" into his discussion of dating “Evaluating Swords."19 Han Hua 韓華 and Di Xiaoxia 狄曉霞 blame the dearth of scholarship concerning "Evaluating Swords" on the fact that Xiang bao jian dao, listed in "Yiwenzhi," is no longer extant. ${ }^{20}$ This appears to assume the two were the same or closely related, as only then would that comparison have been a necessary and productive enterprise.

Despite the variety of opinions scholars have expressed about its derivation, there is no evidence connecting "Evaluating Swords" to any other text. The intelligibility of "Evaluating Swords" as it is, and the

14. Ma Mingda, Shuo jian conggao, 40-42. Zhong Shaoyi, "Gu xiang jian shu chu lun," 358-59 brings up the emergence of the dao in the context of discussing the Hanshu "Yiwenzhi" listing of Xiang bao jiandao; on the suggested shift from jian to dao, see also Mark Edward Lewis, "Swordsmanship and the Socialization of Violence in Early China," in From Athens to Beijing: West Meets East in the Olympic Games, Volume I: Sport, the Body, and Humanism in Ancient Greece and China, ed. Susan Brownell (New York: Greekworks.com, 2011), 155.

Many scholars who have studied this manuscript do not make an explicit division between the manuscript and its content with regard to periodization. They generally date the Juyan sword text following the dates of other material in E.P.T. 40; see e.g. Zhong Shaoyi, "Gu xiang jian shu," 361, and Chen Li, "Juyan xinjian' xiang lishan," 70.

15. Liu Jinhua 劉金華, “Han 'Xiang jian dao ce' lüe shuo” 漢 “相劍刀冊” 略說, Zhongguo lishi wenwu 中國歷史文物 2008.3, 58.

16. Ma Mingda, Shuo jian conggao, 40-42.

17. Ban Gu 班固 (32-92), Hanshu 漢書 (Beijing: Zhonghua shuju, 1962), 30.1775.

18. Li Ling 李零, Zhongguo fangshu kao 中國方術考, rev. ed. (Beijing: Dongfang, 2001), 86-87.

19. Zhong Shaoyi, "Gu xiang jian shu chu lun," 358-59. The relevant point is the relative chronology of different kinds of swords, a point that is useful in dating the text.

20. Han Hua 韓華 and Di Xiaoxia 狄曉霞, “Juyan Han jian 'Xiang bao jian dao' ce yanjiu zongshu” 居延漢簡 “相寶劍刀”冊研究綜述, Sichou zhi lu 絲綢之路 20 (2009), 17. 
lack of any indication that it is an extract, suggest that it is simplest and thus most preferable to treat it as an independent work until evidence emerges to the contrary. This is the approach I follow. Since there is no evidence whatsoever of a relationship with the title Xiang bao jian dao from the Han shu "Yiwen zhi," the complete absence of the term xiang 相 ("to evaluate visually, to physiognomize") underscores that any direct connection between the two is, at best, speculative. In the absence of evidence, asserting a connection between that title and this text is thus more likely to confuse the situation than clarify it.

\section{The State of the Manuscript and Its Text}

The hand that copied out the "Evaluating Swords" manuscript did so in a clear and legible clerical script and the strips we have are very well preserved. ${ }^{21}$ The result is a text that, with the exception of a few graphs, is fairly readable in photographs (see illustration 1). Mostbut not all-problems in the interpretation of the text stem from sentence structure and vocabulary, not handwriting. And there are some significant difficulties in that respect, as I will discuss below.

"Evaluating Swords" as we have it comprises six wooden strips (pine), approximately $22.6 \mathrm{~cm}$ long and $1.2 \mathrm{~cm}$ wide. Each strip contains one line of text, giving a total length of 209 graphs. There are seven bullet points in the text, marking breaks of different sorts; no other punctuation occurs. ${ }^{22}$ There are notches on the strips for three lines of binding, one each at the top and bottom and one in the middle of the strips, but the bindings are not present and the strips are loose. ${ }^{23}$ The separation of the strips invites questions about the sequence and integrity of the text as we have it. Due to the flow of the text and the presence of brief summaries of content in it (see below), there have not been significant questions about the sequence of the strips. The completeness of the text is another matter.

21. The handwriting of this manuscript is thus an example of the dissonance in perceptions that can arise when a particular manuscript is written in a high-quality script, while its content is not evidently of a literary or otherwise elevated nature. See William G. Boltz, "Hand-Writing Styles in Early Chinese Manuscripts," Manuscript Cultures 5 (2012-13), 17-18.

22. I refer to these as "bullet points" in order to be consistent. But while bullet points often indicate emphasis, in early Chinese manuscripts these points also indicate breaks in the text, as the subsequent discussion shows.

23. Liu Jinhua 劉金華, “Han “Xiang jian dao ce' lüe shuo” 漢 “相劍刀冊” 略說， Zhongguo lishi wenwu 中國歷史文物 2008.3, 58-64; Gansusheng bowuguan Han jian zhenglizu, "Juyan Han jian 'Xiang jian dao' ce shiwen," 78 . 


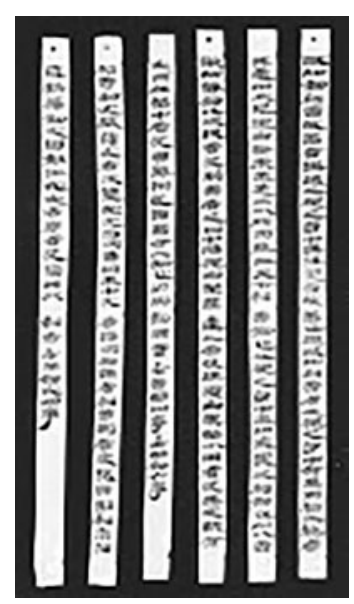

Illustration 1. (Hu Zhi 胡之, ed., Neimenggu Juyan Han jian (er) 內蒙古居延漢簡(二) [Chongqing: Chongqing, 2008], 13.)

The brief introduction to the first published transcription of "Evaluating Swords" asserts that content is missing between the penultimate and final strips. The authors of that transcription posit a discontinuity in the prose at that point, which they believe indicates the absence of at least one strip. Many researchers have accepted this postulation, without speculating about the nature of the missing text. Opinions about the amount of material that was lost have differed. ${ }^{24}$

Not all who have written about "Evaluating Swords" agree that there is a significant break in its text. Liu Jinhua and He Maohuo 何茂活, for instance, separately argue on the basis of structure, textual parallels, and content that the only thing missing is one of the summaries within the text, and not any significant content. He Maohuo suggests the summary in question was, by accident or not, left out when copying and that no strip was lost. ${ }^{25}$

We cannot know with certainty whether "Evaluating Swords" as we have it is complete. This is the nature of writing strips: once they have come unbound, and absent other indications, pretty much anything is possible. Yet the text as it comes to us is intelligible, and I agree with Liu and $\mathrm{He}$ - contra other opinions-that there is no apparent lacuna in the main content. At the same time, there is some material that does not fit into any of the summaries present in the text, suggesting at least one more such summary should exist. Thus, the most parsimonious explanation is that a summary is missing from this copy of the text and nothing else. This essentially matches the proposals of Liu Jinhua and He Maohuo. It is of course impossible to prove this on the basis

24. Gansusheng bowuguan Han jian zhenglizu, "Juyan Han jian 'Xiang jian dao' ce shiwen," 78; see e.g. Han Hua and Di Xiaoxia, 17; cf. also Liu Jinhua, “Han 'Xiang jian dao ce,'" 59 , who himself disagrees (see below).

25. HeMaohuo 何茂活, “Juyan Hanjian 'Xiang jian dao' ce shidu xiyi” 居延漢簡 “相劍 刀” 冊釋讀析疑, in Jianduxue yanjiu 簡牘學研究, no. 5, ed. Xibei shifan daxue lishi wenhua xueyuan 西北師範大學歷史文化學院 and Gansu jiandu bowuguan 甘肅簡牘博物館 (Lanzhou: Gansu renmin, 2014), 96; Liu Jinhua, "Han 'Xiang jian dao ce,'” 59-60. 
of present evidence, and even if proven this would say nothing about the origin of the content or its original state. Ma Mingda's arguments and the archaeological context provide a fair indication that it must come from a time around the middle of the Western Han. The dated materials from the same pit leave us roughly certain that the copy "Evaluating Swords" we now have was in use around the time 9 B.C.E. to 21 C.E.

\section{The Content of "Evaluating Swords"}

In this section, I briefly summarize and discuss the content of "Evaluating Swords." In an attempt at simplicity, I will refer to the text of "Evaluating Swords" by strip sequence and serial numbers, without referring to the transcriptions or otherwise adding notes except as necessary for the discussion here. I explain the interpretive details of difficult words and phrases in the section that follows this one. For citation information and further notes, please see the transcription and translation at the end of this article.

As I mentioned at the outset, "Evaluating Swords" begins with a bullet point and the condition, "If you want to know whether a sword is good and old." The first step in the process to reach that determination follows that condition, which is the direction to "stand and draw it" 起拔之. This reflects that the text bases its evaluations on the blade, not on the pommel, grip, scabbard, or intangible elements.

Since the opening of "Evaluating Swords" refers to both "good" and "old," some scholars have taken these two characteristics in tandem, explaining the text as expressing a simple preference for antiquity that ranks any old sword over any new one because of its value as a mark of social status and as a collector's item. ${ }^{26}$ As Ma Mingda points out, however, a careful reading of "Evaluating Swords" shows it to be practical in focus. For a sword to be old is certainly in its favor; I think this is probably because its quality is proven. But "Evaluating Swords" makes no mention of rarity or special monetary value; nor does it refer to any embellishment, such as one might expect to grace an implement made for show more than for use. Its descriptions concern only things that indicate properties of the blade's metal. This text is not about how to find a collector's item or an antique but rather how to identify a quality sword for use. ${ }^{27}$ There is also no information anywhere in the

26. E.g. Chen Li, “'Juyan xinjian' xiang lishan,” 70; Li Ling, Zhongguo fangshu kao, $86-87$.

27. Ma Mingda, Shuo jian conggao, 35-36; cf. Liu Jinhua "Han 'Xiang jian dao ce,'” $60-61$. 
text about why a particular characteristic indicates good quality, only the insistence that it does so.

The process for identifying an old sword according to "Evaluating Swords" consists of one step: seeing that the main part of the blade lacks remaining marks from metalworking. (It calls these tuichu 推處, a term I discuss below.) After this, "Evaluating Swords" drops the question of whether a given sword is old, going on to discuss three other characteristics indicating good quality. We know there are four characteristics in total identifying a good-quality sword because the fourth strip (E.P.T. 40:205) refers to that number of characteristics in its summary of the section. This indicates that whether a sword is old or not is the first of the four characteristics treated in the opening section of "Evaluating Swords."

The other three good qualities concern the quality of the metal as observable from a visual inspection. "Evaluating Swords" prescribes looking at a blade for the presence of "paired black lines that are unbroken and that at the tip these seem to disappear" 黑兩桁不絕者, 其鋒如不見. This apparently describes a blade that a smith made by fusing two different types of metal together, one light in color and one dark, to give a blade that balances resilience with hardness. High carbon ferrous metal is light in color and, while very hard, also brittle. Lower carbon ferrous metal is darker; it is softer but also tougher and less vulnerable to breaking. The welding together of different metals to achieve a result that balanced the strengths and weaknesses of the two existed in China no later than the third century B.C.E. ${ }^{28}$ This layering seems to be connected to what the text denotes as the "white and hard" 白堅, though it does not use the term here.

The third matter of a good sword concerns the "white and hard"one of the two types of metal I have just discussed-which "Evaluating Swords" says should end before coming to the final third of the blade. He Maohuo and Ma Mingda cite Lüshi chunqiu in this context. $^{29}$ There we find an anonymous evaluator of swords, who explains the makeup of a two-color blade: "The white is that which makes it hard; the yellow is that which makes it tough. If the yellow and the white are mingled, it is both hard and tough, a fine sword"

28. Chen Li, “Juyan xinjian' xiang lishan,” 70; He Maohuo, “Juyan Han jian 'Xiang jian dao,'" 91-92; Donald B. Wagner, Science and Civilisation in China, Volume 5: Chemistry and Chemical Technology; part 11: Ferrous Metallurgy (Cambridge: Cambridge University Press, 2008), 128-34.

29. He Maohuo, "Juyan Han jian 'Xiang jian dao,'" 91-92; Ma Mingda, Shuo jian conggao, 31-32; see also e.g. Zhong Shaoyi, "Gu xiang jian shu chu lun," 358. 
白所以為堅也, 黃所以為物也. 黃白雜則堅且物, 良劍也. ${ }^{30}$ Aside from the difference in color describing the durable metal component-which might result from technological differences, variation in adjective usage, or simply perceptions-the Lüshi chunqiu passage could tally with what we see in "Evaluating Swords" in terms of a two-tone blade. This reading of the Lüshi chunqiu, however, does not accord with the one Joseph Needham presented in his study of ferrous metal technology. He followed Richard Wilhelm's translation of the Lüshi chunqiu, which says that the two kinds of metal are "gemischt" (mixed). Needham thus takes the Lüshi chunqiu passage to describe an alloy rather than welded layers, which then would not fit the descriptions of blades in "Evaluating Swords." 31

What is perhaps unexpected in "Evaluating Swords" is that the lighter-colored material is supposed to appear only in the lower twothirds of the blade, with the final section, at the tip, made up of the darker material only. That the text treats this as a positive trait is made doubly clear below, when it cites the opposite- the two colors extending to the tip-as a negative point. A sword with a tip made up of darker metal only is described as one of the best in the realm, though not yet perfect or even of the highest level. The next sentence, however, names the last of the four positive characteristics, the presence of an “appearance like millet grains" 如㯟粟狀 on the body of the blade, which makes a sword even better. The sense of the text here is clear but the specific significance is obscure. No one who has written on the subject has been able to refer to an instance of this or similar description in an early text, with the predictable result that readers have explained it in different ways. Liu Jinhua, for instance, conjectures that this describes a layer of oxidation with a spotty appearance, which developed on the blade after a special treatment and protected it from decay. ${ }^{32} \mathrm{Ma}$ Mingda refers to stories of famous swords that are supposed to have had patterned blades. He says that this particular pattern resulted from the wrought steel construction of the blade, which as a result developed a spotted layer of oxidation on the body (as opposed to the edge). ${ }^{33}$ Chen $\mathrm{Li}$ 陳力 explains this as describing the places where the dark and the light metals come together, which would be of a different

30. Chen Qiyou, Lüshi chunqiu xin jiaoshi, 25.1651.

31. Richard Wilhelm, Frühling und Herbst des Lü Bu We (Jena: E. Diederichs, 1928), 435; Joseph Needham, The Development of Iron and Steel Technology in China (Cambridge: The Newcomen Society, 1958), 1.

32. Liu Jinhua, "Han 'Xiang jian dao ce,'" 62.

33. Ma Mingda, Shuo jian conggao, 34-35. 
appearance on the body of the sword than on its edge. ${ }^{34}$ I find Chen Li's explanation most persuasive because it continues the focus on the intrinsic quality of the metal itself, rather than introducing new factors. Chen's explanation furthermore tallies well with images of wootz and damascene blades that I find online. But there is at present no certainty about what exactly might have created a millet grain appearance on a sword. This ends the section of Part 1 that discusses good characteristics of swords and the second strip.

"Evaluating Swords" next turns to the characteristics of poor swords. Like the preceding section, which dealt with good swords, this one begins with a bullet point. While the bullet point marks a break, the summary at the end of the fourth strip (E.P.T. 40:205) implies that everything preceding it, regarding both good and poor swords, forms one section. I thus treat this also as a portion of Part 1.

This section begins, like the previous does, by addressing and defining its audience: "• One who wishes to know if a sword is poor and so not to use it, or that it is new equipment" - 欲知弊劍以不报者, 及新器者. This brings out the distinction between a poor sword and a new one by means of an explicit "and" ( $j i$ 及), making the separation even stronger than the opening of "Evaluating Swords" does when it distinguishes good swords and old ones. This separates new swords from those necessarily bad, which leads me to think that the objection to a new sword is less absolute than to a bad one. In conjunction with the preference for old equipment I have already discussed, I suggest this advice is intended to help the one evaluating a sword for use avoid an untested blade in favor of something of proven reliability.

"Evaluating Swords" begins its discussion of bad swords and new ones with the command to go into the sun and make a careful visual inspection. Just as the lines created by layers of lighter and darker metal were supposed to disappear before the tip of a good sword, so is their continuation to the tip the mark of a poor one. Similarly, the presence of gouging marks a bad sword, just as the absence of such marking was characteristic of a good one. The dark and light metal should also not be "clearly separated," perhaps because that would reflect an imperfect or incomplete welding process.

Finally, the text discusses patterning on a blade. Chen Li understands this to refer to patterns created by processes of hardening and tempering the blade; he believes the text has shifted its focus from the metal intrinsic to a blade to changes in appearance due to those processes. ${ }^{35}$ There is no doubt that early metal- and swordsmiths in China knew and

34. Chen $\mathrm{Li}$, “Juyan xinjian' xiang lishan," 70.

35. Chen Li, "Juyan xinjian' xiang lishan," 72-73. 
employed techniques of hardening and tempering, including quenching in a variety of liquids. Processes like those can indeed leave patterns on the surface a metal object. ${ }^{36}$ In the present case, however, I believe the patterns discussed are more likely to be those of the metal itself and not those left by quenching or something else, for two reasons. First is the absence of any indication of a shift in topic, without which continuation of the preceding topic is likely. Second is the conclusion of this subsection, which says that the preceding characteristics are those of "swords from poor welders," suggesting again that the text continues the focus on the formation of the weapon-i.e., the work of the smith.

In this section, patterns indicate poor quality in several ways. One way is when the patterns follow the length of the sword in the hard portion of the blade. A continuous swirling pattern also reflects a poor sword. This section says in closing that its provisions apply equally to swords (jian) and sabres (dao). This is the only place the latter term occurs in this text; this seems like it could be a later addition to a previously existing text about swords (jian) to make explicit that its advice applies also to sabres. This section closes with the internal summary giving the numbers of matters of good swords and bad that it treats: four and six, respectively.

The final part of "Evaluating Swords" talks about specific patterns and final characteristics of blades that are desirable and those that are not. The patterns are described in an impressionistic manner, the preferable ones being "Hanging Curtains," "Bearing Paired Snakes," "Holding Feathers," and "Jade Tablet"; those to avoid are "Fighting Cocks" and "Writhing Snakes." Obviously it is impossible to know what these mean specifically but the general sense is clear.

This last section also reiterates that the focus of "Evaluating Swords" is on appearance, asking rhetorically, "If a strong one could have a bad exterior appearance, what would a weak one be like?" and noting that a coarse appearance is a sign of bad quality. The entire thing ends with a final summary, which mentions only the four qualities of bad swords.

\section{The Structure of the Text}

Bullet points appear in "Evaluating Swords" at the top of the first strip and three others (E.P.T. 40:202, E.P.T. 40:204, E.P.T. 40:206, and E.P.T. 40:207), in each case beginning a short section concerning one type of judgment. Bullet points are widely seen in excavated materials and

36. Wagner, Science and Civilisation, 133-37; Wagner, Iron and Steel in Ancient China, 274-82; Chen Li, "Juyan xinjian' xiang lishan," 72-73; Ma Mingda, Shuojian conggao, $31-32$. 
often serve to signal the start of a sentence or section or to mark another sort of break. Establishing breaks like this is helpful for the reader; even more useful is an indication of how its segments group together, and the internal summaries in "Evaluating Swords" serve this purpose.

At the end of the third strip (E.P.T. 40:205) comes "• The preceding are four matters of good swords. - The preceding are six matters of bad swords" - 右善劍四事 - 右弊劍六事. These two labels have bullet points that divide them from the preceding prose text and from each other. Most useful, in terms of analyzing the structure of the text, is the information they provide about the quantity of decision criteria, which helps parse the material and establishes the first main division of the text. ${ }^{37}$

Due to the absence of other punctuation, the number of points of evaluation for a good sword would be at least potentially ambiguous without the summary's indication that there are four. Knowing that there are four, however, suggests that the occurrence of four instances of the word shi 視, "to look," at the beginning of sentences describing characteristics of good swords is more than just repetition. He Maohuo notes the pattern and argues that it marks a parallel structure, with each of four sentences beginning shi, in one case (second strip, E.P.T. 40:203) prefaced with you 又, "also, again." Although not all scholars accept this division, the symmetry of four instances and four characteristics, as well as the parallel structure of the sentences, indicates to me that this is the best approach. ${ }^{38}$ The closing words of "Evaluating Swords" form a final summary that encapsulates not the entire text but only the last four points as "matters of poor swords."

\section{Problems of Interpretation}

There are several terms and phrases that pose difficulties in reading "Evaluating Swords." 39 One of these is numbered among the decisive characteristics of a sword: the text refers to tuichu 推處, the absence of which indicates an old sword. This binome does not appear in this context in received texts. It has thus, inevitably, occasioned some interpretive creativity on the part of readers. Ma Mingda proposes that tuichu is a commoners' term for the quillons of a sword. He says that Chunqiuperiod bronze swords had either no crossguards or only very small

37. See also Liu Jinhua, "Han 'Xiang jian dao ce,'" 59.

38. He Maohuo, "Juyan Han jian 'Xiang jian dao' ce," 94; cf. Chen Li, "Juyan xinjian' xiang lishan," 71-72.

39. For citation information and further details of philological and text-critical interest, please see the text and annotated translation at the end of this article. 
ones, and as such their absence would mark an "old sword." Ma admits that there is no support for his reading other than its sense in this context. ${ }^{40}$ A more important shortcoming is the fact that he does not link this with the rest of "Evaluating Swords" and its focus on steel swords and practical use. He Maohuo suggests instead that tuichu denotes places where the blade has been damaged by being struck by another blade. It is not obvious why the absence of such damage would indicate an old sword and he does not explain this point. ${ }^{41} \mathrm{Li}$ Ling proposes that tuichu denotes the division between two colors indicating different types of metal, without canonical support for his reading or explaining why it would identify the blade as an old one. ${ }^{42}$

Chen Li takes tuichu as marks in the metal left over from the process of making the sword. He offers two possible lines of reasoning to reach this conclusion. The first is the simplest, taking the components of tuichu in their usual senses to give "push places," which he explains as "shoveling," i.e., gouges in the metal left behind from initial working of the blade. Alternately, he suggests tui 推 could also be written here for chui 椎, "hammer; to hammer," which would mean "hammer places," i.e., hammer marks from forging that remained on the blade. Both suggestions seem to me very reasonable. However they came to be, in Chen's proposal the marks would have worn away over time through maintenance and use, their absence thus indicating age. ${ }^{43}$ While the lack of canonical examples of tuichu makes a final determination impossible at present, I concur with Liu Jinhua that Chen Li's explanation is the best that has been offered so far. ${ }^{44}$

The phrase I translate "paired black lines" is hei liang heng 黑兩桁. The color "black" (hei 黑) is clear without further clarification. Liang 兩, usually "two," I understand following He Maohuo to function verbally, "to be two, to be paired." Heng 桁 means "purlin(s)," horizontal roof rafters, and is here used metaphorically to refer to the appearance of

40. Ma Mingda, Shuo jian conggao, 29-31; also Ma Mingda, "Zhongguo gudai de xiang jian fa," 61-62.

41. He Maohuo "Juyan Han jian 'Xiang jian dao' ce," 90-91. He suggests taking 推 as "to stab," thus tuichu as "places that have been stabbed," and also allows for the possibility that 推處 means a spot that is "pushed" (i.e., bent) on the blade.

42. Li Ling, Zhongguo fangshu kao, 86-87, says that 白堅 and 黑堅 are two types of work on the sword, and suggests that tuichu 推處 is the division between those two.

43. Chen Li, "Juyan xinjian' xiang lishan," $70-73$.

44. Liu Jinhua 劉金華, “Han 'Xiang jian dao ce' lüe shuo” 漢 “相劍刀冊” 略說, Zhongguo lishi wenwu 中國歷史文物 2008.3, 61. He notes that distinguishing between "new" and "old" focuses on tuichu 推處. When discussing the various explanations of “推處," he says that he finds Chen Li's explanation relatively good. 
the layers of metal. ${ }^{45}$ A blade that "seems to be invisible" 如不見 accompanies these lines in the metal. This last point likely refers to a keen edge in terms familiar to anyone who has successfully sharpened a knife.

When the text discusses the characteristics of a poor sword, it relates the result of reaching such a conclusion on the third strip (E.P.T. 40:204) with a phrase that is difficult to understand. All published transcriptions have the three graphs in question as yi bubao 以不報, and the photographs leave no doubt that this is the proper transcription of the first two characters. The identification of the third character (previously bao 報), however, gives cause for uncertainty. The phrase yi bubao is itself by all accounts difficult to understand, due mainly to the presence of the word that previous transcriptions unanimously read as bao 報, which usually means "to repay, requite, respond." The idea of a sword that does not repay is not familiar from other texts. Some authors who have treated "Evaluating Swords" suggest that this repayment refers to bringing good luck. These authors do not support their reasoning with references to other texts. Presumably they have in mind usages like that occurring in the aphorism "Hidden virtue always has an evident reward (bao)" 陰德必有陽報. Versions of that saying appear in a number of Han texts, sometimes with "heaven" (tian 天) named as the source of the reward, but often not. ${ }^{46}$ The context in "Evaluating Swords," however, concerns quality rather than luck, and the unusual nature of this interpretation with reference to a weapon leaves me doubtful.

Examination of the published photographs of this strip increases my doubts about this identification. Comparison of the graph generally transcribed as bao 報 with the examples listed in Lu Xixing's 陸錫興 Handai jiandu caozibian 漢代簡牘草字編 confirms that the right part of the graph is like that of bao in other contemporary manuscripts, namely forming $f u$ ₹. The left-hand part, however, is different from that in other examples of bao, in that it has a hard angle leading to a long stroke to the left at the bottom (see illustration 2). This difference is not enough to make identification of the graph as bao impossible, and the unanimity of previous readers is, of course, not without reasonable basis. Yet the combination of an unusual semantic sense and an unusual graphic form makes me think another reading may be preferable.

45. He Maohuo, "Juyan Han jian 'Xiang jian dao' ce," 92.

46. For one well-known example, see the "Ren jian xun" 人閒訓 chapter of Huainanzi 淮南子; He Ning 何䁇, Huainanzi jishi 淮南子集釋 (Beijing: Zhonghua, 1998), 18.1254. 


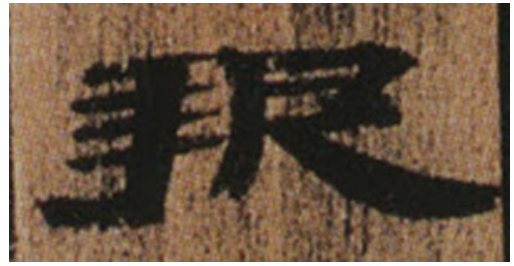

Illustration 2. (colour online) (Hu Zhi, 13.)

I suggest that this graph is a previously unattested variant of $f u$ 服. There are two parts to this identification. The first part is the easier and concerns usage. There are many examples of $f u$ 服 used in the sense of "to bear (a sword)." The examples easiest to locate come in dictionaries like Ciyuan 辭源 and Hanyu dacidian 漢語大詞典, which list the phrase fujian 服劍, “to wear a sword, to bear a sword." ${ }^{47}$ Moreover, the word $f u$ 服 has, among its many senses in the dictionaries, the meanings "to use" 任用 and “to bear in the hand" 執持. Understanding yi bufu 以不服, “in order not to bear (that sword)," would therefore be a straightforward reading in this context.

The second part of the identification concerns the form of the graph. Shuowen jiezi 說文解字 says that $f u$ 庋 is the phonetic element of the graph $f u$ 服, which it glosses as "to use." 48 I suggest the left part of the graph in "Evaluating Swords" is an anomalous shou f, "hand," with an additional horizontal stroke, an attested manuscript form. ${ }^{49}$

Read in this fashion, a standardized modern version of the graph before us would be 报, read as fu and meaning "to bear, to use." This character is of course in use in the People's Republic of China today as the simplified form of bao 報, which perhaps contributes to the more common identification of the character in transcriptions of "Evaluating Swords." There are also broader semantic and phonological connections between $b a o$ and $f u$, which provide some incidental support for the relationship between the two. ${ }^{50}$ I suggest that in the Han manuscript context, it is permissible in terms of graphic form and preferable in

47. Hanyu dacidian, s.v., "fujian." It lists examples including the "Xiu wu xun" 脩務 訓 chapter of Huainanzi, which says, "One who bears a sword expects sharpness and does not expect a Moyang or a Moye" 服劍者期於銛利,而不期於墨陽、莫邪; see He Ning, Huainanzi jishi, 19.1361.

48. Xu Shen 許慎 (d. c. 120 C.E.), Shuowen jiezi (Beijing: Zhonghua, 1963), 176.

49. My approach to graphic variation is informed by that of William G. Boltz, as seen, e.g., in Boltz, "Character Variation in Early Chinese Manuscripts," Manuscript Cultures 5 (2012-13), 76-83; and Boltz, "Orthographic Variation in Early Chinese Manuscripts," Acta Orientalia Academiae Scientianim Hungaricae 62.1 (2009), 89-113; I also learned a great deal from Matthias Richter, Embodied Text. For the version of shou 手 I mention, see Pan Chonggui 潘重規, Dunhuang suzi pu 敦煌俗字譜 (Taipei: Shimen tushu gongsi, 1978), 120.

50. See discussion and examples in $\mathrm{Wu}$ Shanshu 吳善述 (nineteenth century) Shuowen guangyi jiaoding 說文廣義校訂 (Qucheng: Zhang Wenjin zhai, preface dated 1874), 3.73b-74a. 
sense to take the character to be 报, read in context as fu, "to bear," which gives my translation.

In reading further along in the third strip (E.P.T. 40:204), I again propose an interpretation that is unlike any published opinion. Previous transcriptions have in the text there xing 騂, "brownish red," usually describing the color of a horse or an ox. Ma Mingda suggests this denotes a yellowish-red color in the metal of the blade resulting from the oxidation of impurities left by inferior workmanship. ${ }^{51}$ The problem with this reading is the position of the graph in the sentence, before the verb "to look at," whereas in that sense one would expect it to follow the verb. Chen Li proposes reading xing as a loan for qie 輩, "to lift in the hand(s), to suspend," giving the direction to "lift and look at it." This is reasonable in terms of sense and the alternation between xing and qie is attested in other sources, yet the lack of phonetic or graphic similarity raises questions about a general interchangeability between the two. ${ }^{52}$ Moreover, my examination of the photographs of the strip suggests that the previous transcription may be incorrect. ${ }^{53}$ At the very least, the character in question is not a standard version of xing. For while xing is composed of ma 馬 and xin 辛, the graph appears to be instead 䮵, comprised of the radical $m a$ and the phonetic element $d a$ / $t a$ 羍 (see illustration 3). This character is also unlike the example of xing that $\mathrm{Lu}$ Xixing lists from among Han manuscripts. ${ }^{54}$

As in the previous case, the published reading is certainly possible. Yet the combination of interpretive difficulty and graphic variation again leads me to think the best reading may differ from earlier suggestions, and I propose a novel graphic variation. The left-hand part of this graph, typically the semantic portion, is clearly ma 馬, "horse." As noted already, the right-hand portion, apparently the phonetic element, is $\mathrm{da}$ / $t a$ 幸. On the basis of the shared phonetic element I suggest the graph 䮃 is a graphic variant or loan for the word $d a$ 達, "to reach, achieve." There is a conceptual relationship between the semantic elements of the two variants. Chuo 定/之, the radical of $d a$ 達, often indicates a connection with movement or travel; $m a$ as a semantic element can do the same for equestrian travel and sometimes by extension for other forms of travel, too. ${ }^{55} \mathrm{Da}$ furthermore works well in terms of sense here, as

51. Ma Mingda, Shuo jian conggao, 35 .

52. Gao Heng 高亨, Guzi tongia huidian 古字通假匯典 (Ji'nan: Qi-Lu shu she, 1989), 100.

53. See particularly Hu Zhi 胡之, ed., Neimenggu Juyan Han jian (er) 內蒙古居延漢簡 (二), 15 .

54. Lu Xixing, Handai jiandu caozi bian, 195.

55. E.g. chi 馳, "to race (toward), to go fast." 


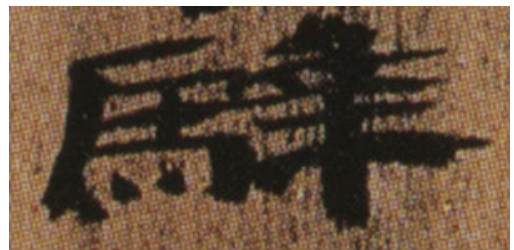

Illustration 3. (colour online) (Hu Zhi, 13.)

together with the next graph it forms the binome dashi 達視, “to look at carefully," which is attested in received Han texts and logical in context. ${ }^{56}$

After listing various negative characteristics of swords, the fourth strip (E.P.T. 40:205) says that all are bi he ren 幣(:弊)合人 swords. The content of the preceding strip and this one (i.e., E.P.T. 40:204 and E.P.T. 40:205) flows together seamlessly, producing a list of six characteristics. And as I noted above, strip four (E.P.T. 40:205) ends by saying, "The preceding are six matters of poor swords." This last point makes it certain that the phrase bi he ren refers to the preceding poor swords. $B i$ 幣(:弊) occurs repeatedly in the text in the sense of "bad" and ren 人, "person," seems obvious enough. But the three words together leave the sense of the word he 合, usually "together; to meet together; to close," difficult to comprehend. He Maohuo, for instance, acknowledges the difficulty and proposes understanding the phrase as referring to swords that are of poor quality and yet can "go with (he) a person." He explains this as describing swords that are not "good" but are also not unpropitious. ${ }^{57}$ Yet the general practical and concrete focus of "Evaluating Swords" makes me doubt this reading, to say nothing of the unusual usage and the non-standard grammatical structure it demands.

The word he 合 can refer to bringing together or combining things. Thus, Chen Li suggests that here it means metal "alloy." Chen explains away "person" (ren 人) in this line by calling it an error for the grammatical particle zhi 之. In his reading, the phrase is bi he zhi jian 弊合之劍, “a sword of poor alloy." 58 While attractive in terms of sense, the problem with this interpretation is that the character for "person" in this text is clear and not similar to that of $z h i$, which appears repeatedly elsewhere in "Evaluating Swords." Nevertheless, I think Chen is correct to understand this phrase as denoting, in some way, the material quality of the blade.

56. See Hanyu dacidian, s.v., "dashi." At the 2015 University of Chicago Creel Center workshop presentation mentioned above, Han Wei 韓偉 suggested alternatively that the graph 䮵 could be an error for $n i$ 逆, "to reverse, go against." In context this would instruct the user to examine the blade from another angle, which is also a reasonable reading.

57. He Maohuo, "Juyan Han jian 'Xiang jian dao,'" 92-93.

58. Chen Li, "Juyan xinjian' xiang lishan," 72 . 
Chen Li's interpretation informs mine but my understanding differs from his in two main respects. First, since the preceding phrases refer to patterns in the blade resulting from layers of metal, I take he to mean not "to alloy" but rather "to weld" 59 together, i.e., the process of forming the blade from multiple pieces of metal, resulting in the layering already discussed. I take "person" (ren) as written. Together, I suggest, the two words heren 合人 refer to the "welder," i.e., the person who carried out that task in the manufacture of the blade. Zhouli 周禮, probably dating to the late Warring States period, contains numerous examples of titles comprising a noun or verb plus "person." 60 In my reading, bi heren jian means "swords from poor welders," which were lowquality blades exhibiting characteristic patterns that a buyer should avoid.

\section{Translation of "Evaluating Swords"}

My transcription, punctuation, and translation draws from a number of previously published versions and related research articles. ${ }^{61}$ The transcription as reproduced here as a rule employs standardized modern versions of all characters, with a few graphs that are not part of standard character sets. As I mentioned in the introduction, the original strips are not numbered and contain no punctuation other than bullet points. I insert sequential numbers and include also the archaeological serial numbers for ease of reference. In the translation I insert the sequential numbers in square brackets at the corresponding places.

59. In present-day common usage, the word "weld" has potentially anachronistic implications of gas or electric welding; its strict sense is in fact broader.

6o. On dating Zhouli and its broad influence on Warring States conceptions of government, see David Schaberg, "The Zhouli as Constitutional Text," in Premodern East Asian Statecraft in Comparative Context: The Rituals of Zhou in Chinese and East Asian History, ed. Benjamin A. Elman and Martin Kern (Leiden: Brill, 2010), 33-63.

61. Transcription and photos of the original are in Hu Zhi 胡之, ed., Neimenggu Juyan Han jian (er) 內蒙古居延漢簡(二) (Chongqing: Chongqing, 2008), transcription and main photo 13, close-up photos pp. 14-19; see also the transcription in Ma Yi and Zhang Rongqiang, Juyan xinjian shijiao, 145-46; and He Maohuo, "Juyan Han jian 'Xiang jian dao' ce," 85-98, including his translation of the text on p. 97. The first published transcription of this text was in Gansusheng bowuguan Han jian zhenglizu 甘肅省博物館漢簡整理組, “Juyan Han jian 'Xiang jian dao' ce shiwen” 居延漢簡 “相劍刀” 冊釋文, Dunhuangxu jikan 敦煌學輯刊 3 (1983), 78. In the course of reading the text, I referred also to Chen Li 陳力, “'Juyan xinjian' xiang lishan daojian zhujian xuanshi” “居延新簡” 相利善刀劍諸簡選釋, Kaogu yu wenwu 考古與文物 2002.6, 70-73; and Ma Mingda, Shuo jian conggao, 27-44. Additional references are cited individually. 
1 - 欲知劍利善故器者, 起拔之, 視之身中無推處者, 故器也. 視欲知利 善者，必視之身中有黑兩桁不絕者，(E.P.T. 40:202)

2 其逢(:鋒) 62 如不見. 視白堅未至逢(:鋒)三分所而絕, 此天下利善劍也. 又視之身中生如㯟粟狀, 利劍也, 加以善. (E.P.T. 40:203)

3 - 欲知幣(:弊) $)^{63}$ 劍以不报(:服) 64 者, 及新器者, 之日中, 䮵(:達) 65 視白 堅隨逢66 上者及推處、白黑堅分眀者，及無文、縱有 (E.P.T. 40:204)

4 文而在堅中者, 及雲氣相遂, 皆幣(:弊)合人劍也. 刀與劍同等 - 右善 劍四事・右幣(:弊)劍六事. (E.P.T. 40:205)

5 - 利善劍文: 縣(:懸)薄文者保雙虵文皆可. 帶羽圭中文者皆可. 劍鳪 (:鳴 $)^{67}$ 者利善. 強者表葸(:惡), ${ }^{68}$ 弱則利奈何? (E.P.T. 40:206)

62. Writing feng 逢 for feng 鋒 also occurs in other excavated texts; see Wang Hui 王輝, Guwenzi tongjia shili 古文字通假釋例 (Taipei: Yiwen yinshuguan, 1993), 555.

63. The text consistently writes $b i$ 幣, usually “currency, cloth currency," for $b i$ 弊, "poor, bad." This alternation is known in received texts, including the record of a stele inscription in Hong Kuo 洪适 (1117-84), Li shi 隸釋, Skqs, 7.5a-6a; see also Gao Heng, Guzi tongjia huidian, 594-96, which lists supporting examples. Tomiya Itaru 冨谷至, et al., eds., Kankan go-i: Chūgoku kodai mokkan jiten 漢簡語彙: 中国古代木簡辞典 (Tokyo: Iwanami Shoten, 2015), 502-3, list $b i$ 幣 as an alternate form of $b i$ 粫, "to be worn out, broken, damaged," with reference to other texts. He Maohuo, "Juyan Han jian 'Xiang jian dao,'" 87, insists upon reading this instance of $b i$ 幣 as $b i$ 弊 and not $b i$ 敝, concentrating on the latter's implication of a poor condition resulting from use or damage. It seems likely that $b i$ 弊 and $b i$ 糤 represent what was originally one word, which developed closely related meanings and graphic distinctions over time.

64. See discussion of this graph and its interpretation in the introductory section of this article.

65. See discussion of this character and its interpretation in the introduction.

66. Hu Zhi's transcription has 蓬, Ma and Zhang have 凊, and He Maohuo has 垐. To my eye the photo seems to show 逢.

67. No one has yet proposed a fully satisfactory reading of this graph. The published photographs of the graph show clearly that the left-hand portion is the radical 言, as all readers agree. The right-hand portion is not immediately evident. Ma and Zhang and other readers understand the graph as qian 謙, usually "modest; inferior." The first transcription has liang 諒. In context that could mean "of good faith, trustworthy," though Ma Mingda, "“Juyan Han jian 'Xiang jian dao,'” 86, explains it as a loan for liang 稤. Ma then adduces the Shuowen jiezi 說文解字 quotation of a lost Erya 爾雅 entry that defines liang 椋 as “thin"; Xu Shen, Shuowen jiezi, 181. Ma next refers to the excavated military text Sun Bin bingfa 孫臏兵法, which says, "If a blade is not thin, it will not cut" 刃不溥(:薄)則不刺; see Zhang Zhenze 張震澤, Sun Bin bingfa jiaoli 孫臏兵法校理 (Beijing: Zhonghua shuju, 1984), 130. It may be noted that the Shuowen jiezi first defines liang as a term denoting something bad; see Tang Kejing 湯可敬, Shuowen jiezi jinshi 說文解字今釋 (Changsha: Yuelu shushe, 1997), 1197-98. This suggests that the sense "thin" Shuowen jiezi employs is not intended as praise.

He Maohuo, "Juyan Han jian 'Xiang jian dao' ce," 88-89, acknowledges the previous readings and rejects them on the basis of both form and sense. He suggests reading 


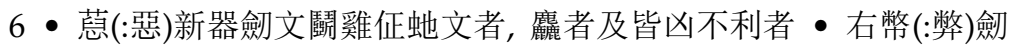
文四事 (E.P.T. 40:207)

[1] • One who wishes to know whether a sword is good and old should stand and draw it. If you look at it and the body has no gouging, it is old equipment. One who, looking at [a sword] wishes to know if it is a good one, should always look to see that in its body there are paired black lines that are unbroken [2] and that at the tip these seem to disappear. If you look and see that the white and hard ends before reaching the last third, this is a good sword of the realm. If you see also that the body has in it an appearance like millet grains and it is sharp, it is even better.

[3] - One who wishes to know if a sword is poor and so not to bear it, ${ }^{69}$ or that it is new equipment, should go into the sunlight. If, when you look carefully, ${ }^{70}$ the white and hard follows up the tip; or there is gouging, or the black and the hard are clearly separated; or there is no patterning, or along the length there is [4] patterning and it is in the hard; or the clouds and ether (i.e., swirling patterns) follow each other; then these are all swords from poor welders. ${ }^{71}$ Sabres and swords are of the same sort.

- The preceding are four matters of good swords. • The preceding are six matters of bad swords.

[5] - Patterns on a good sword: "Hanging curtains" and "Bearing paired snakes" are both acceptable. "Holding feathers" and "Jade tablet" are both acceptable. A sword that sings is good. If a strong one could have a bad exterior appearance, what would a weak one be like?

instead as 鳪, which in context he proposes as a variant of ming 鳴, “to call, sing, ring." He refers to the Hanyu dacidian 漢語大詞典, s.v., "mingjian" 鳴劍, which cites example uses and explains that mingjian denotes a good sword. He Maohuo forthrightly acknowledges three problems with his reading, including the fact that the identification of the character in the published photographs remains a question. The graph 鳪 is furthermore not attested in any source, although it would adhere to the usual principles for creating graphs. Finally, the following text refers to "strong ones" 強者 and “weak ones" 弱者， which are not of a type with the proposed reading of "singing." Nevertheless, I find He Maohuo's reading best fits the available evidence and so I adopt it provisionally.

68. Ma and Zhang and others have 蒠 here. According to the Dictionary of Character Variants website, this is another form of $x \breve{\imath}$ 葸, "to fear," also the name of a plant; see http://dict.variants.moe.edu.tw/yitib/frb/frbo3957.htm, accessed 1 April 2015. Hanyu dazidian 漢語大字典, 3264, says the same. All readers agree that in this context it is a form of $e / w u$ 惡, "bad; to be bad."

69. See discussion of this reading in the introduction.

70. See discussion in the introduction regarding $d a / t a$ 䮵(:達).

71 . On this line, see discussion in the introduction. 
[6] Bad new equipment with the sword [blade] patterns of "Fighting cocks" or "Writhing snakes," and those of coarse make, are all unpropitious and poor. - The preceding are four matters of poor swords.

\title{
居延地區出土鑑定劍刀質量指南
}

\author{
陳力強
}

\section{提要}

本文介紹及翻譯居延地區出土文獻裏面的漢朝或新莽時期鑑定鋼鐵劍 刀質量指南. 許多學者將此篇當作 “相寶劍刀” 但是此論點仍有可商榷 之處. 拙作介紹鑑定劍刀質量指南的時代與考古背景，針對較難了解的 用詞作分析，並將原文翻成英文.

Keywords: Han-Xin, excavated texts, swords, steel 漢, 新莽, 出土文獻, 劍, 鋼鐵 